\title{
Object-Relational Modelling and Establishment of a Generic Database for the Management and Monitoring of Urban Planning Permissions in the City of El-Eulma (Algeria)
}

\author{
Ahmed AKAKBA', Abdelwahhab FILALI ${ }^{2}$ \\ ${ }^{1}$ University of Batna 2, Earth and Universe Sciences Institute, Department of Geography, Fesdis, Wilaya of Batna, ALGERIA \\ ${ }^{2}$ University of Batna 2, Laboratory of Natural Hazards and Spatial Planning (LRNAT), Fesdis, Wilaya of Batna, ALGERIA \\ E-mail: djalal.akakba@gmail.com, abdelwahhabfilali@gmail.com \\ DOI: 10.24193/JSSP.2017.2.07 \\ https://doi.org/10.24193/JSSP.2017.2.07
}

K e y w o r d s: urban planning reports, Land Use Plan, cadastral plan, GIS, object-relational modelling

\begin{abstract}
A B S T R A C T
The decision to issue urban planning permissions (e.g.: deeds) at the local communities level in Algeria is based on the cadastral plan (land administration) which defines the owners of the land and the Land Use Plan (LUP, French: POS); in turn, LUP defines the allocation of land and the applicable planning rules. The aim of the present task is therefore to contribute to the development of a Georeferenced database that would enable us to exploit LUP data (geometric and attribute) as well as the cadastral plan. This approach would allow us to produce a wide range of spatialized, structured and standardized information, thus facilitating the provision of planning documents, the preparation of fiscal reports, the evaluation of spatio-temporal changes, etc. The modelling of data is based on the object-relational modelling adopted by ESRI; this model has been built using the extension "ArcInfo UML Model" integrated in Microsoft Visio. Importing the model into a geodatabase module is done using the "ESRI Schema Creation Wizard" available in ArcCatalog. Furthermore, a municipal one-stop shop for all the formalities required, which was recently established by Decree \#19/15, brings together stakeholders in a single commission to deal with all relevant cases of El-Eulma city. The Geomatics approach adopted is a Geo-decisional tool for the one-stop-shop allowing for a good diffusion and communication of information in real time.
\end{abstract}

\section{INTRODUCTION}

The complexity of data in the field of urban planning and land management presents a challenge for urban planners. The intervention of different sectors makes the task even more multidisciplinary with multisource plans, thus negatively impacting data quality. Moreover, the scale of intervention of each sector makes coordination difficult for issuing urban planning permissions because of the red tape and an unmanageable volume of information to exchange and monitor. This situation eventually amplifies the conflicts between multi data sources.

The city of El-Eulma, where this study took place, has recently experienced considerable demographic and urban development. It has become a regional hub of wholesale trade, which in turn has resulted in an unbridled increase in requests for urban planning permissions.

This situation of accelerated urban growth has clearly demonstrated that there is a blatant lack of an appropriate tool for dealing with information from different bodies involved in the field (cadastre, municipality, town planning, hydraulics services, etc.). However, the current large variety, number, and relationships of urban planning-related data that should be processed and analyzed to make sustainable land use decisions demand the support of Geographic Information System (GIS) processing and its analytical advantages [1].

Multidisciplinary approaches and extensive numbers of plans, that do not necessarily have the same 
scale, generate ambiguity as to the area of intervention of the actors involved. This work purports switching from classical methods to numerical approaches. The generic modelling of different plans (LUP and cadastral plan) would allow the creation a relational database that would facilitate the processing of heterogeneous data for the management of imperfections and thus reduce the uncertainty of data supplied.

Similarly, the Geographic Information System (GIS) technology has given a new insight to addressing a variety of resource development, management and planning activities [2].

The objective of this work is to adopt a spatialization tool for digital geographic information to replace traditional maps and static plans. These intelligent plans must correspond to interactive digitization. Moreover, this exhaustive database makes it possible to adjust the Geo-referencing of different plans to reduce graphic tolerance.

On the basis of the results obtained, we can say that we were able to create an effective communication and coordination tool between owners, tax department and the technical department of Town Planning. This tool must be applied rigorously in order to update the database and insure the retention of the associated history.

\section{STUDY AREA}

The strategic situation of the city of El-Eulma is of great importance as it is located at the intersection between several important roads, particularly National Road number 05, connecting Constantine and Algiers, National Road number 77 linking Beni-Aziz and the city of Batna, as well as the Constantine-Algiers railway line.

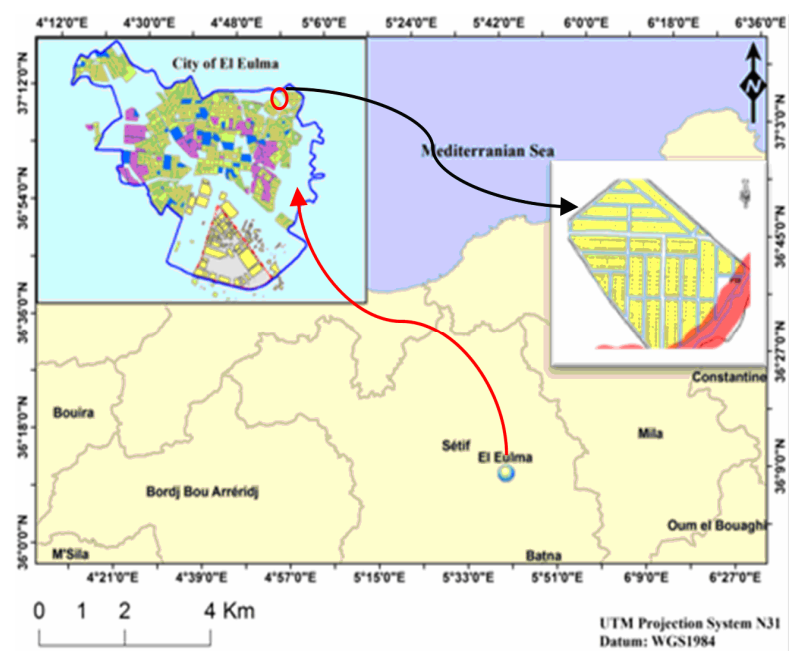

Fig. 1. Location of the study area.

Our focus in this study was the $\mathrm{LUP}_{35}$ in Figure 1, which represents an unlawfully built neighbourhood where urban planning rules are brushed aside. The appearance of this type of neighbourhood began at first as a scattered settlement with no building permits on a very fragmented agricultural land. It should be noted that the growth of the city converges substantially with unplanned neighbourhoods presenting an unbalanced conurbation.

This conundrum forced the local stakeholders to integrate these neighbourhoods within the urban perimeter. This state of affairs redefines the urban planning objectives, thus allowing for new operations of restructuring and land regularization.

\section{LITERATURE REVIEW}

Lemmen et al (2003) noted that Cadastral systems are, mainly, the same: they are all based on the relationships between people and land, via (property) rights and are in most countries influenced by developments in the Information and Communication Technology (ICT) [3].

According to Cichocinski (1999) a modern or digital cadastre should answer two basic questions [4]: 1) What is at a particular location?; 2) Where are certain conditions to be found?. On the other hand, Tuladhar (2002) argues that at an international level a substantial effort should be directed towards the modelling of cadastral systems; complex structures comprised of a lot of sub-systems and processes, supported by databases maintaining the land referenced data [5]. It has also been observed that cadastral systems must serve a multipurpose use and thereby meet the challenge of a modern GIS and IT environment [6].

Thus, Carter and Bounhom (2007) noted that computerization of land administration activities, involving the creation of a digital cadastre as part of Spatial Data Infrastructure (SDI), is considered necessary to improve data access, usability, and coordination of land related activities [7].

\section{METHODOLOGICAL APPROACH}

For the implementation a digital cadastral database, a variety of factors can be taken into consideration as prerequisites [8]. The geomatics approach that we have adopted for the management of planning permissions through municipal one-stop shops has led to a better understanding of the threesided relationship between plot ownership, land use and taxation.

The geographic database obtained provides three levels of geographic information (geometric, semantic and topological) relating to the development plans and the local cadastral plan.

This work sets out a three step process as follows: i. firstly, showing the heterogeneity and confusion of data between the cadastre (land registry office) and the urban plans; ii. secondly, designing a 
generic database to expedite interactions and homogeneity at the one-stop shop; iii. thirdly, querying the database for land regularization of illegal settlements and providing the new landlords with compliant urban planning. The following diagram shows the transition from the classical approach to the geomatics approach:

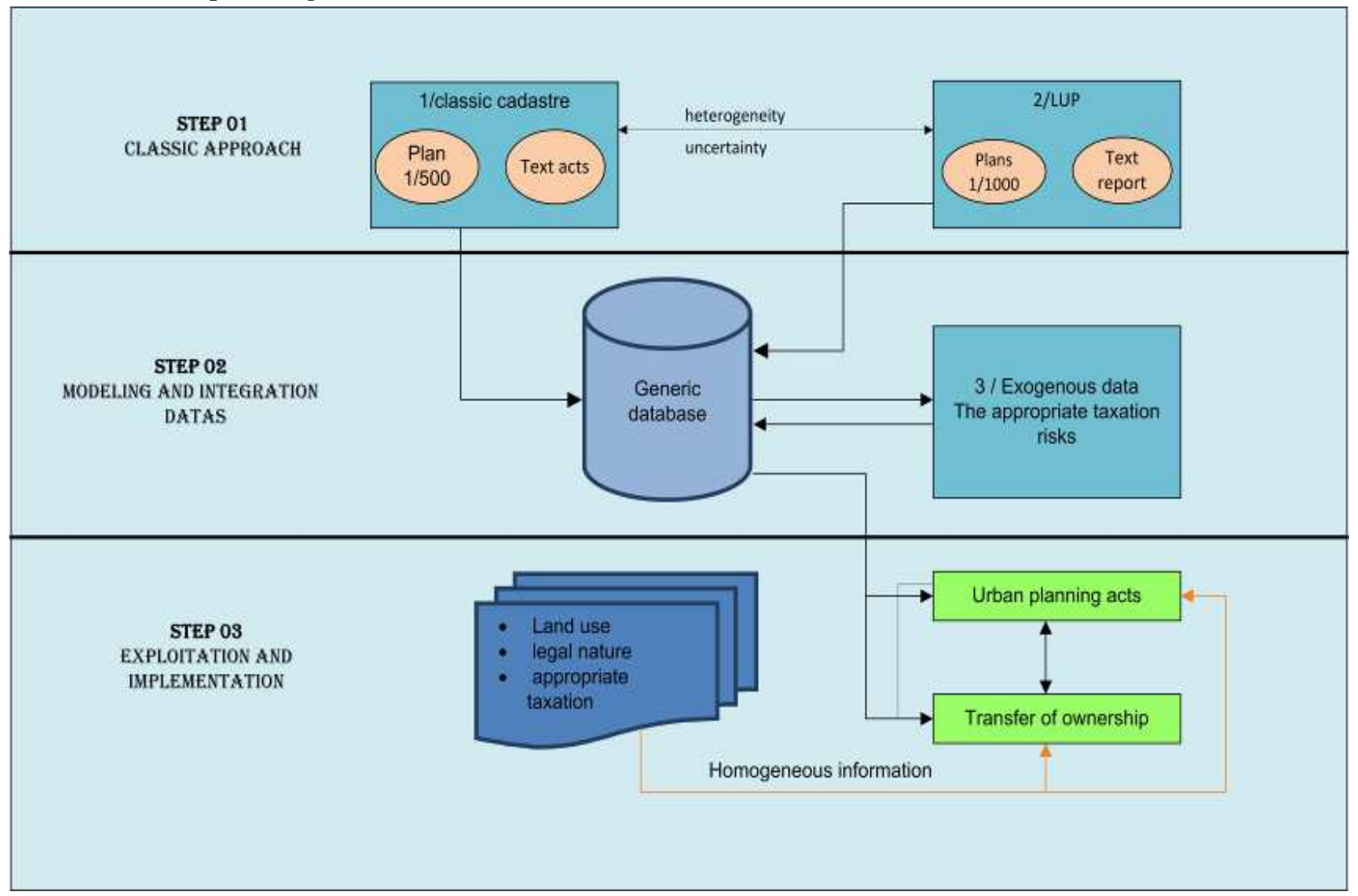

Fig. 2. City of Eulma, Geomatization of urban planning acts.

The modelling of data is based on the objectrelational modelling adopted by the ESRI; this model was built by using the extension "ArcInfo UML Model" integrated in the Visio software. Importing the model into a geodatabase in the ArcCatalog module is done using the "ESRI Schema Creation Wizard" available in ArcCatalog.

\subsection{Monitoring data evolution over time}

Monitoring data evolution over time is essential to observe the geometrical and descriptive changes of the city blocks in order to update the database and preserve the associated history. The validity of information of an urban planning permission remains legitimate until the next sale or subdivision operations. The information is organized in different layers and under different themes; a structure that allows users and analysts to understand the movement and status of cadastral information [9].

The database developed is the result of the daily compilation of two types of operations: the cadastral operation of land regularization of illegal constructions and the delivery of urban planning permissions. It is from this database that we can follow the geometric and descriptive changes as a function of time.

From a practical point of view, the different values taken by the attribute over time are retained, each associated with a temporal element that describes its validity period [10].

Based on the cadastral experience of the Quebec province [11], our study aims to reduce or eliminate any kind of anomalies that may result from the possible geometric and descriptive changes of any plot in order to ensure a reliable sale or inheritance operation.

Table 1 shows that plot (004), which is planned to undergo changes, must obey the following rules:

- Plot (004) marked O (original) will be split into two for a sale transaction of one part;

- the first carries registration number (00567) including a date of sale, while the second plot was coded under number (00568) but keeping the same information relative to the original plot (004). This tabular data allowed us to ensure the update and preserve the history of the existing plot patterns. 
The "previous batch code" reflects the origin of the property before cadastral regeneration, in our database the previous batch code can have several values:

Table 1. Geometric and descriptive changes as a function of time.
The $\mathrm{O}$ value reflects the original plot status, The ON value reflects undivided ownership (indivision) or co-ownership.

\begin{tabular}{|c|c|c|c|c|c|c|}
\hline \multirow{2}{*}{ Phase } & $\begin{array}{c}\text { Plot } \\
\text { Code }\end{array}$ & $\begin{array}{c}\text { Previous } \\
\text { Plot }\end{array}$ & Date & Owner & & \\
\hline \multirow{3}{*}{ Set up } & 1 & ON & dd mm yyyy & & & \\
\cline { 2 - 7 } & 2 & O & dd mm yyyy & & & \\
\cline { 2 - 7 } & 3 & O & dd mm yyyy & & After \\
\cline { 2 - 7 } Implementation & 567 & O & 4 & 22.03 .2017 & & 5 \\
\cline { 2 - 7 } & 568 & 4 & 05.03 .2015 & 4 & 5 \\
\hline
\end{tabular}

\subsection{Plans and planning reports}

The Land Use Plan is a regulatory legal instrument for urban and communal management, Figure 3. It is mandatory for the municipality which initiates it in order to lay down specific rules for the urbanization of parts or all of its territory and the composition of their built environment. (Act No. 9029). Its aim is to regulate the large number of urban planning permissions (construction, allotment and demolition). Furthermore, granting urban planning permissions depends on the cadastral plan, so it is essential to generate a correlation between land ownership and land use.

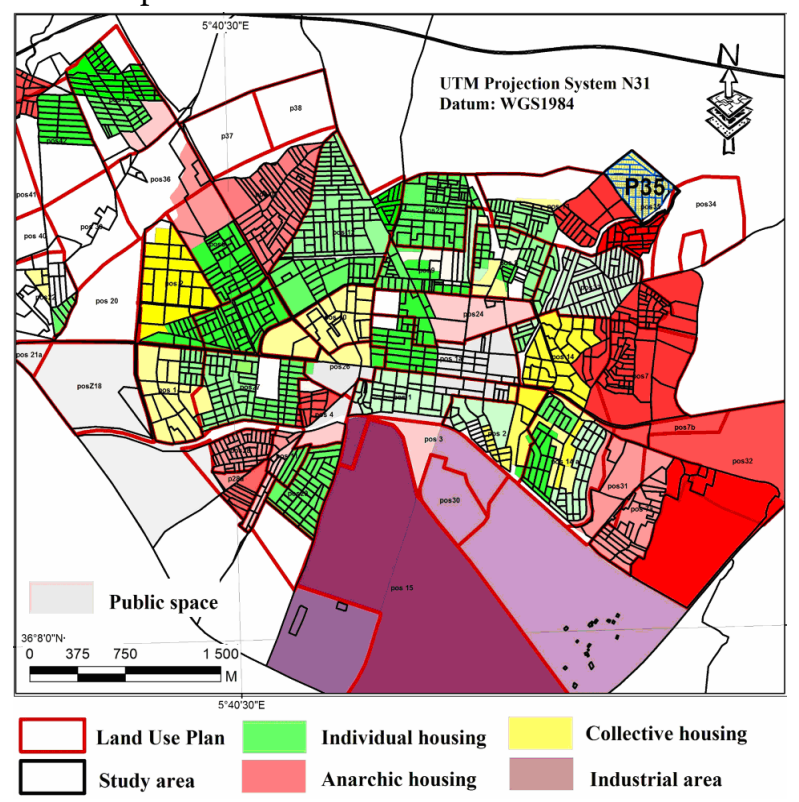

Fig. 3. El-Eulma city, LUP zoning.

The planning certificate, the subdivision (allotment) permit, the separation certificate, the building permit, the conformity certificate and the demolition permit, indicated in the relevant articles of Law no. 90-29 of 1 December 1990 are issued by the municipality. In order to process these urban planning acts, there are several administrative documents that must be presented (example the deed of ownership) to the municipality before file processing.

The decision to issue urban planning acts constitutes the final stage (implementation) of operational planning or the convergence and the tripartite relationship between land ownership, land use and appropriate taxation. In Algeria, the cadastre identifies and fixes the boundaries of land properties, and provides a tax assessment. The issue at stake lies in the fact that the urban planning rules are not given proper consideration when elsewhere it has been deemed essential to integrate urban planning rules within the cadastral system in order to create a generic database allowing an appropriate land management as illustrated by the International Federation of surveyors (FIG) in its Declaration on Land Administration and Sustainable Development [12].

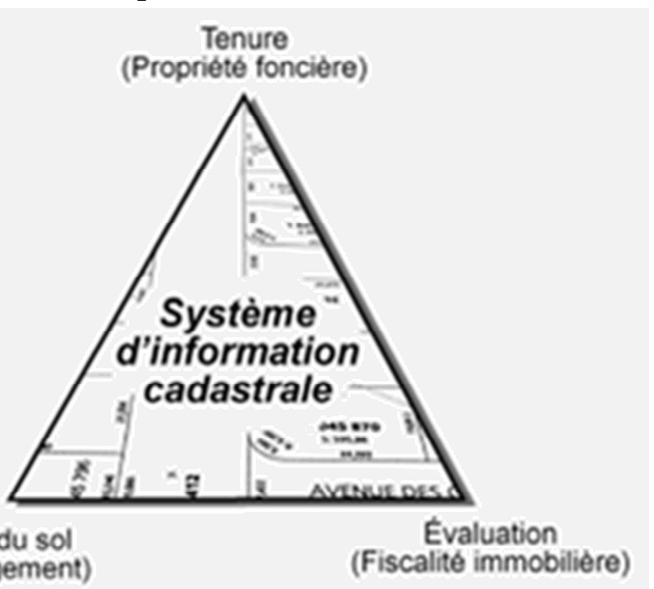

Fig. 4. The tripartite of the cadastral information system.

This declaration aims to clarify the role and contributions of cadastral systems in territorial governance and social equity: land policy development, urban growth management, vulnerability to natural 
disasters, etc. [13]. In addition, the work of Dale and Mac Laughlin (1999) on land administration offers a conceptual model that integrates these new cadastral issues: economic (assessment and taxation), legal (tenure and property) and policy (land use) [14].

This model makes it possible to illustrate the concept of a cadastral information system (see Fig. 4).

\subsection{The one-stop-shop}

The one-stop-shop is a mechanism that has been set up by the Algerian government and is to be installed at the level of each municipality to strengthen local governance. The mission of the one-stop shop is to facilitate the process of issuing urban planning reports as soon as possible through inter-sectoral collaboration.

Our original objective is the digitization by integrating Geomatics that will serve as a database containing all the inter-sectoral information needed by administrators to manage land space.

\section{OBJECT-RELATIONAL MODELING}

Spatial modelling generally focuses on the geometric, topological properties and attributes of spatial objects. Indeed, a spatial model reflects the perception of the designer of spatial objects [15]. Modelling data means, in fine, drawing a diagram. Building data allows us to avoid unwanted redundancies, to ensure their safety and their extensibility.

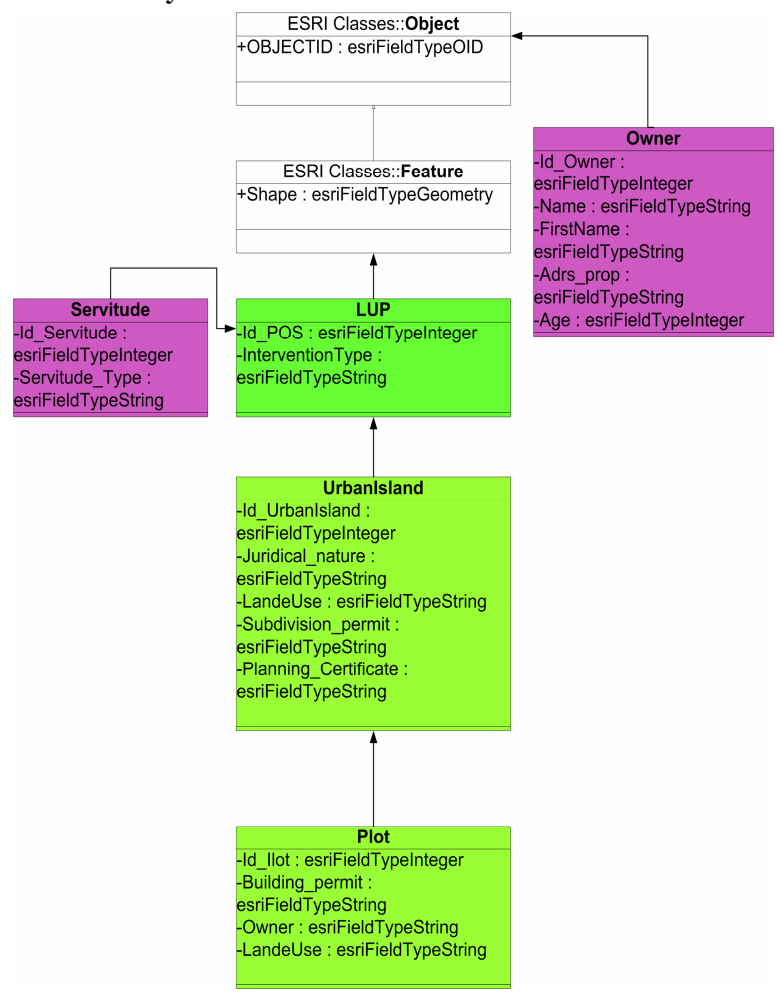

Fig. 5. Object-relational modelling data.
The functionalities of GIS are basically those of the DBMS to which are associated functions of map display, spatial analysis and thematic processing [16].

The object-relational modelling adopted is created using the CASE tool in the Visio software; the CASE tool is a set of integrated programs and application development tools that help in software development [17], using the diagram of UML class. UML is widely accepted in software applications, especially in most GIS software such as ESRI's ArcGIS which directly supports it.

From conceptual data model CDM, which is independent of any physical platform, the logical data model LDM, which is similar to the CDM, (Fig. 5), must obey the object-relational modelling proposed by ESRI through the use of the model "ArcInfo UML Model" directly integrated into Visio.

\subsection{Importing and verifying the model}

The LDM must be imported into XML (Extensible Markup Language) that can be directly used for the creation of a Geodatabase under ArcInfo (import, with ESRI CASE tool, faithful in terms of relational structure and topologies [18]. the model ("Semantic Checker") is used to identify errors in the LDM figure (05). Once the model is corrected, the creation of the physical data model (PDM) as a Geodatabase is done thanks to the "ESRI Schema Creation Wizard" available in ArcCatalog.

\subsection{Data integration and implementation}

A spatial database is the storage of geographic data in a prescribed format, including the location, shape, and description of geographical features as well as the relationships between different features [19]. Integration of geographic data according to the following three dimensions: integration or drawing of the geometric dimension (vector) in feature classes, insertion of topological rules between different entities such as disjunction, proximity relationships, inclusion with the production of a topological report illustrating drawing errors for correction, insertion of the semantic dimension of entity classes into tables.

According to [20], a spatial database usually includes co-ordinates and topological information. The integration of the topological rules between the feature classes in this GIS application shows the forbidden interaction between the layers (easements, risk) and the new implantation in an urban block (coloured in red).

Among the advantages of the GIS approach is the link between the generalization of information between different entity classes a several levels of urban analysis. For example, the UMP (Urban Master Plan, French: PDAU) consists of several LUPs, the latter 
consisting of a set of blocks. This technique allows us to work on a single high-resolution cartographic medium with a flow of information that ensures consistency between the levels of planning and operational intervention.

The entity class LUP determines the type of intervention in the whole urban fabric by orientations (restructuring of the chaotic districts), in the same support the entity class urban BLOCK allows us to issue urban planning permissions and the operation processing as part of the overall town planning strategy (Fig. 6).

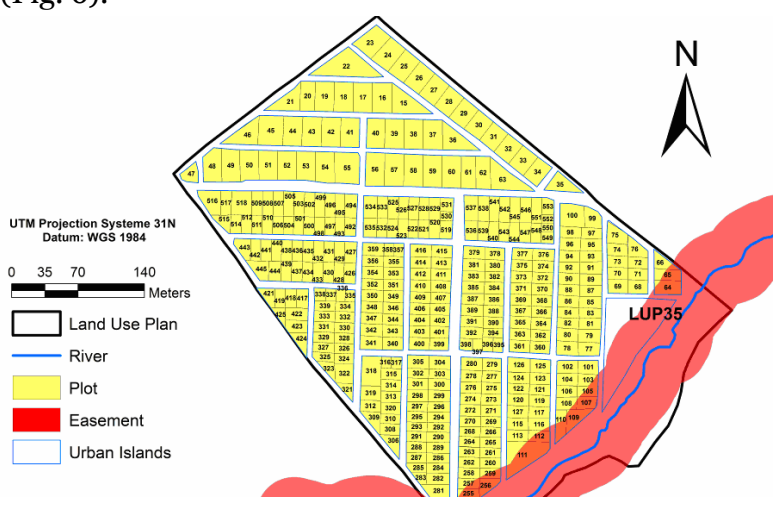

Fig. 6. Land Use Plan (LUP) carried out under a cadastral plan.

\section{RESULTS AND DISCUSSION}

The exploitation of the geographical database by the decision-makers enables them to reduce the response period from 30 to 10 days only, when it comes to issue urban planning permissions adapted to real needs.

To illustrate the feasibility of the approach adopted, two proposals had been considered; an application for urbanization at LUP35 level, an application for a construction permit that will be granted or rejected (Fig. 7).

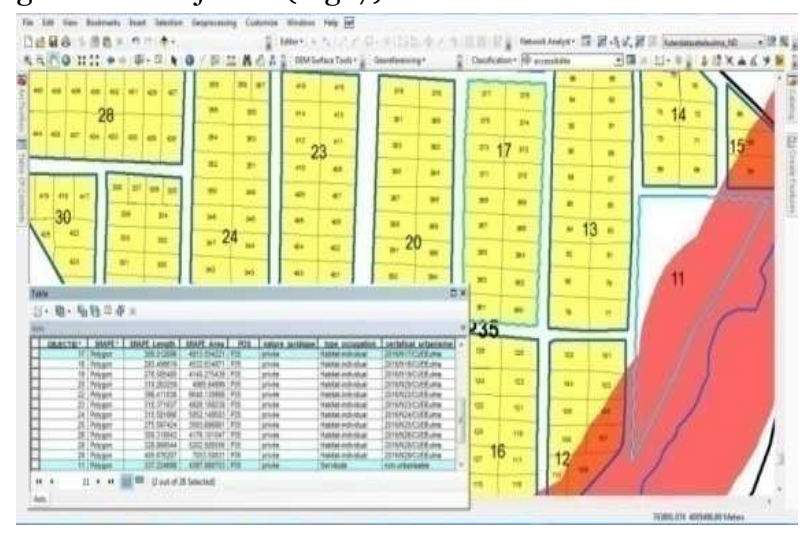

Fig. 7. Example of actions related to urban planning

acts.

Land use at urban block level (17) aims to give various uses to the different parts of the LUP. The allocation of these assignments is based on a large number of structured information in the attribute table that was compliant with the cadastral plan.

Indeed, for a construction permit to be granted, a number of requirements must be met and correlated with a subdivision permit, a land use plan and the legal nature of the project.

On the other hand, the request to build a new construction was rejected for block (11) due to conflicts with the orientations introduced in the database (Type of occupancy, easement). The effectiveness of this method relies on the updated information provided by the cadastral and tax services. Therefore, the success of the one-stop shop depends on the active participation of all relevant sectors.

\section{CONCLUSION}

In order to meet the requirements of the local authorities of El-Eulma in terms of management and monitoring of urban planning reports, it is vital to model urban and cadastral plans. This generic applied modelling is an asset in order to improve the fluidity of geographic information for all sectoral or territorial intervention operations.

The results obtained led to:

a). The preservation of protected areas through the regulatory orientation of new urban development projects and the detection of illegal constructions in non-building land areas.

b). The availability and quick access to information with the ability to update and decisionmaking in real time using an acceptable justification.

c). The ease of reading the territory and carried out fiscal balances in the meetings of the communal council, allows to make an inventory of places including the geolocation of the buildings to be regularized or demolished.

d). The query of the database providing us with all the information concerning the non-regulatory plots with precise details on the attributes (ownership), which facilitates the operations of the delivery of urban planning reports and the land regularization of illegal constructions.

\section{REFERENCES}

[1] Shcherbina, O., Shembelyeva, E., Trusins, J. (2010), Spatial Development Decision Making and Modelling, Scientific Journal of RTU, vol. 1, pp.25-31. Available at: https://ortus.rtu.lv/science/lv/publica tions /8928/fulltext. Last accessed: $13^{\text {th }}$ February, 2017. [2] Zahir, A., Muhammad, S. (2013), Implementing GIS-based Cadastral and Land Information System in Pakistan, Journal of Settlements and Spatial Planning, vol. 3, issue 1(2012), pp.43-49. Available at: https:// www.researchgate.net/publication/228097678. Last accessed: $14^{\text {th }}$ March, 2017. 
[3] Lemmen, C., Molen, P., Oosterom. P., Ploeger, H., Quak, W., Stoter, J., Zevenbergen, J. (2003), A Modular Standard for the Cadastral Domain. Available at: https://repository.tudelft.nl /islandora/object/uuid:82f9da80-2fff-4631-8590-ade 59c21e402? collection=research, / Last accessed: 03 November 2017.

[4] Cichocinski, P. (1999), Digital Cadastral Maps in Land Information Systems. A Journal of LIBER Quarterly vol. 9, pp. 211-221, Munich, Germany. Available at http://www.galaxy.uci.agh.edu.pl/ cichocin. Last accessed: 4 November 2016.

[5] Tuladhar, A. (2002), Why Is Unified Modelling Language (UML) for Cadastral Systems? $3^{\text {rd }}$ workshop and $4^{\text {th }}$ MC meeting of the COST G9 action: Modelling real property transactions, 10-12 October, Delft, the Netherlands.

[6] Enemark, S., Sevatdal, H. (1999), Cadastres, Land Information Systems and Planning- is decentralisation a significant key to sustainable development? in UN-FIG Conference on Land Tenure and Cadastral Infrastructures for Sustainable Development: Melbourne, Australia.

[7] Carter, D., Bounhom, H. (2007), Moving from a Successful to a Modern Cadastre in Lao PDR."TS 6A Case Studies on Land Administration Projects in Asia and the Pacific, pp 1-14, Strategic Integration of Surveying Services, FIG Working Week 2007. Hong Kong SAR, China, May 13-17 2007.

[8] Ali, Z., Tuladhar, A. M., Zevenbergen, J. A. (2010), Developing a Framework for Improving the Quality of a Deteriorated Land Administration System Based on an Exploratory Case Study in Pakistan, Nordic Journal of Surveying and Real Estate Research, vol.7, issue 1, pp. 30-57. Available at: http://journal.fi/njs/article /view /3661/3430. Last accessed: 27th April, 2017.

[9] Cichocinski, P. (1999), Digital cadastral maps in Land Information Systems Liber quarterly, the journal of European research libraries, vol. 9, issue 2. Available at: DOI: http://doi.org/10.18352/lq.7535. Last accessed: 20th April 2017.

[10] Parent, C., Spaccapietra, S., Zimányi, E., Donini, P., Plazanet, C., Vangenot, C., Rognon, N., Crausaz, P. A. (1997), MADS, modèle conceptuel spatio-temporel [MADS, a spatial-temporal conceptual model], Revue Internationale de Géomatique, vol. 7, issue 3/4, pp.317-352. Available at: https://infoscience. epfl.ch/record/99094 /files/geomatique98.pdf. Last accessed: $17^{\text {th }}$ January, 2017.
[11] Guide de l'utilisateur version informatique. (2002), Le plan du cadastre du Quèbec [The Quèbec cadastral plan], Bibliothèque nationale de Quèbec, 2002, ISBN: 2-551-21627-3

[12] FIG (1999), the Bathurst Declaration on Land Administration for Sustainable Development, Bathurst Workshop on Land Tenure and Cadastral Infrastructures for Sustainable Development, Bathurst, Australia, pp. 22.

[13] Francis, R. (2006), Le développement de systèmes cadastraux pour un aménagement durable du territoire [Cadastral systems development for sustainable spatial planning], Cahiers de géographie du Québec, vol.50, issue 141,pp. 361-369. Available at: DOI: 10.7202/014877ar. Last accessed: $15^{\text {th }}$ February, 2017.

[14] Dale P., Mac Laughlin J. (1999), Land Administration, Oxford, Oxford University Press.

[15] Chokri, K. (2011), Implantation d'un système d'information géographique $3 D$ sur internet pour la gestion des modèles urbain [Implementation of a $3 \mathrm{D}$ GIS on the Internet for the management of urban models], thèse de doctorat, spécialité géomatiqueinformatique, université de Strasbourg. Available at: scd-theses.u-strasbg.fr/2131/o1/KOUSSA_Chokri_20 11. pdf. Last accessed: $18^{\text {th }}$ May, 2017.

[16] Garnier, B. (2006), Etude de mise en œuvre d'un système d'information géographique partage au sein des services du conseil général de Haute Loire [Study of the implementation of an geographical information sharing system within the services of the General Council of Haute Loire], mémoire master, Université Jean Monnet Saint-Etienne, pp. 69.

[17] Kang, M. A., Pinet, F., Schneider, M., Chanet, J. P., Vigier, F. (2004), How to Design Geographic Databases? Specific UML Profile and Spatial OCL Applied to Wireless Ad Hoc Networks. Heraklion, Crete. $7^{\text {th }}$ AGILE Conference on Geographic Information Science.

[18] ESRI (2006), Building a geodatabase, GIS by ESRI, Redlands, USA, pp. 460.

[19] Rigaux, P., Scholl, M., Voisard, A. (2002), Spatial Databases: With Application to GIS. London, Morgan Kaufmann Publishers.

[20] Zainal, A. M. (2006), from geospatial data capture to the delivery of gis-ready information: improved management within a GIS environment. PhD Thesis, University of Newcastle, School of Civil Engineering and Geosciences. Available at: https://theses.ncl.ac.uk/dspace/bitstream/10443/680/ 1/Majeedo6.pdf, pp. 24. Last accessed: $15^{\text {th }}$ June, 2017. 